\title{
diseñar un espacio para voces reflexivas. relacionar el ethos del zine con la indagación filosófica dirigida por jóvenes ${ }^{1}$
}

\author{
natalie $\mathrm{m}$. fletcher ${ }^{2}$ \\ concordia university, canada
}

resumen

Este artículo se esfuerza por establecer una base teórica necesaria para justificar una alianza entre el zining y la investigación filosófica impulsada por jóvenes, dos prácticas importantes que operan fuera de la corriente principal, pero que pueden arrojar luz sobre las (in)comprensiones convencionales de la juventud al ilustrar formas innovadoras de diseñar espacio para que voces jóvenes surjan y prosperen en sus experiencias educativas y más allá. Al resaltar el ethos compartido entre el zining y la comunidad de investigación filosófica (CIF) como prácticas que fomentan la creación de significado, este artículo pretende enfatizar sus rasgos comunes, a saber: participativos, hágalo usted mismo, experimentales, politizantes y transformadores, al tiempo que toma nota de los retos involucrados al extenderlos al contexto de la infancia. Además, ilustra cómo alinear el zining y la investigación filosófica pueden contribuir a una re-visión de los niños al retratarlos como productores culturales capaces e historiadores sociales de sus propias comunidades discursivas. Por último, explora cuestiones de autoridad adulta, sugiriendo condiciones que pueden ayudar a autenticar el uso filosófico de zines con jóvenes dentro del modelo CIF y proporcionar grandes ventajas a la juventud, incluyendo un mayor acceso a múltiples formas de aprendizaje a través de proyectos interdisciplinarios, relaciones más equalizadas con adultos, una gama de disposiciones creativas y pensantes que pueden mejorar su autoeficacia y un sentido genuino de que sus voces importan. Sostiene que, como embajadores de la voz, el zine y la investigación filosófica tienen mucho que enseñarse, especialmente con respecto a la representación de los jóvenes como pensadores capaces y con ideas dignas de compartir.

palabras clave: zining; Investigación filosófica impulsada por jóvenes; autoridad

\section{desenhar um espaço para vozes reflexivas. relacionar o ethos do zine com a indagação filosófica dirigida por jovens.}

resumo

Este artigo se esforça por estabelecer uma base teórica necessária para justificar uma aliança entre o zining e a investigação filosófica impulsionada por jovens, duas práticas importantes que operam fora da corrente principal, mas que podem jogar luz sobre as (in)compreensões convencionais da juventude ao ilustrar formas inovadoras de desenhar espaço para que vozes jovens surjam e prosperem em suas experiências educativas e para além delas. Ao ressaltar o ethos compartilhado entre zining e a comunidade de investigação filosófica (CIF)

\footnotetext{
${ }^{1}$ Este texto conquistó el Premio a la Excelencia en Filosofía para Niños del Consejo Internacional para la Investigación Filosófica con niños, 2016. Traducción de Carolina Martinez (Université du Québec à Montréal).

2 E-mail: nataliefletcher@gmail.com
} 
diseñar un espacio para voces reflexivas. relacionar el ethos del zine con la indagación filosófica dirigida por jóvenes

como práticas que fomentam a criação de significado, este artigo pretende enfatizar seus traços comuns, a saber: participativos, faça você mesmo, experimentais, politizantes e transformadores, ao tempo que toma nota dos desafios envolvidos ao estendê-los ao contexto da infância. Além disso, ilustra como alinhar o zining e a investigação filosófica pode contribuir com uma re-visão das crianças ao retratá-los como produtores culturais capazes e historiadores sociais de suas próprias comunidades discursivas. Por último, explora questões de autoridade adulta, sugerindo condições que possam ajudar a autenticar o uso filosófico do zines com jovens dentro do modelo CIF e proporcionar grandes vantagens à juventude, incluindo um maior acesso a múltiplas formas de aprendizagem através de projetos interdisciplinares, relações mais equalizadas com adultos, uma gama de disposições criativas e pensantes que podem melhorar sua auto eficácia e um sentido genuíno de que suas vozes importam. Sustenta que, como embaixadores da voz, o zine e a investigação filosófica têm muito que se ensinar, especialmente com respeito à representação dos jovens como pensadores capazes e com ideias dignas de compartilhar.

palavras-chave: zining; investigação filosófica impulsionada por jovens; autoridade

\section{designing a space for thoughtful voices. aligning the ethos of zines with youth-driven philosophical inquiry}

abstract

This article strives to lay some necessary theoretical groundwork for justifying an alliance between zining and youth-driven philosophical inquiry-two important practices that operate outside the mainstream yet can shed light on conventional (mis)understandings of youth by illustrating innovative ways of designing space for young voices to emerge and thrive in their educational experiences and beyond. By highlighting the shared ethos between zining and the Community of Philosophical Inquiry as practices that foster meaning-making, this article aims to emphasize their common participatory, do-it-yourself, experimental, politicizing and transformative features, while noting the challenges involved in extending them to the context of childhood. Further, it illustrates how aligning zining and philosophical inquiry can contribute to a re-envisioning of children by portraying them as capable cultural producers and social historians of their own discourse communities. Lastly, it explores issues of adult authority, suggesting conditions that may help to authenticate the philosophical use of zines with youth within the CPI model and provide great advantages to youth, including increased access to multiple ways of learning through interdisciplinary projects, more equalized relationships with adults, a range of creative and thinking dispositions that can enhance their self-efficacy, and a genuine sense that their voices matter. It argues that as ambassadors for voice, zining and philosophical inquiry have much to teach one another, especially with regard to depicting youth as capable, considerate thinkers with ideas worth sharing.

keywords: zining; young-driven philosophical inquiry; authority. 
diseñar un espacio para voces reflexivas. relacionar el ethos del zine con la indagación filosófica dirigida por jóvenes

Aquellos que no tienen el poder también son capaces de crear una cultura - una que surja de su forma de entender el mundo. -Stephen Duncombe, Notes from Underground: Zines and the Politics of Alternative Culture

Una filósofa de ocho años está sentada frente a un pequeño cuaderno pensando en lo que va a escribir a continuación. Sumergida en sus ideas sobre la naturaleza de la imaginación después de un animado diálogo con otros niños sobre la posibilidad de imaginar algo que no existe. En una explosión de inspiración, garabatea sus ideas antes de lanzarse a dibujar emocionadamente, ilustrando lo que sería el mundo sin imaginación. La niña arruga su papel, luego lo alisa y colorea de marrón las arrugas para lograr realmente lo que quiere. Algunos momentos más tarde comparte sus resultados con sus amigos, intercambiando sus cuadernos y comparando sus creaciones, riendo de lo que resulta de sus intentos por interpretar lo que los otros imaginaron. “¡En el colegio nunca logro hacer esto!” exclama emocionada. Ella la llama una experiencia liberadora. Nosotros le llamamos su filozine: una autopublicación de sus pensamientos y divagaciones realizada a partir de un bricolaje de medios mixtos; la combinación de indagación filosófica y zining adaptado (aunque de forma menos drástica de lo que uno podría suponer) para niños.

Los filozines son una contribución pertinente para el movimiento zining -mini publicaciones que tratan la filosofía como una forma creativa en que los niños pueden embarcarse en la fascinante complejidad de la vida a través de sugerencias abiertas diseñadas para hacer surgir la curiosidad y la expresión multifacética-. Más allá de su utilidad en diferentes objetivos de aprendizaje, desde mejorar la alfabetización pasando por el razonamiento crítico hasta la habilidad artística, los filozines actúan como recordatorios concretos de que la capacidad para asombrarse propia de la niñez no debe deslegitimarse como un importante promotor de la voz reflexiva. Los filozines 
diseñar un espacio para voces reflexivas. relacionar el ethos del zine con la indagación filosófica dirigida por jóvenes

son la creación de Brila, un organismo educativo canadiense de caridad creado para inspirar a los jóvenes a través del diálogo filosófico y proyectos creativos en contextos de aprendizaje informal ${ }^{3}$. Como miembro del movimiento internacional de Filosofía para Niños (FpN). Brila utiliza el modelo pedagógico de la Comunidad de Indagación Filosófica (CIF) en su programa educativo para reconocer el amor de los jóvenes por el pensamiento y crear un espacio para su construcción colaborativa con la esperanza de activar intercambios en el diálogo que darán voz a su búsqueda de construcción de significado ${ }^{4}$. Como practicante acreditada de $\mathrm{FpN}$, he sido testigo de las epifanías transformadoras que los jóvenes han tenido cuando sus voces son tomadas en serio e incluso he visto formas en que Brila extiende sus experiencias en CIF con proyectos creativos que ofrecen una evidencia tangible de sus esfuerzos -artefactos filosóficos como los filozines que testifican el discernimiento en sus pensamientos-. Aunque varios esfuerzos creativos son candidatos válidos, una aventura ha sido para mí la más atractiva y prometedora: el zining.

El zining, una forma radical de la autopublicación que pronto celebra sus cien años, ha permitido a las voces anónimas experimentar con expresiones creativas a partir de sus propios términos a través de mini publicaciones que encarnan ideas de gran importancia desde la política y el trabajo hasta el arte y la cultura. El zining y la indagación filosófica son aliados claros como prácticas que conciernen al diseño de un espacio para voces pensantes. El espíritu del zining puede ofrecer a la juventud oportunidades inestimables para tener más arraigo, sentir y vivir el sentido existencial de sus diálogos en la comunidad de indagación filosófica CIF, mientras se

${ }^{3}$ Para más información sobre la misión de caridad y los programas de Brila, y para ver sus zines digitales por favor visite: www.brila.org.

4 Adaptando las ideas pragmáticas de Charles Sanders Peirce y de John Dewey, Matthew Lipman (2003, 200-201) diseñó el programa P4C para fomentar el pensamiento multidimensional (o la combinación de pensamiento crítico, creativo y afectivo), que él veía como "un balance entre lo cognitivo y lo afectivo, entre lo perceptivo y lo conceptual, entre lo físico y lo mental". Lipman creía que el modelo CPI podría proveer a los jóvenes los medios para abordar las cuestiones que ellos consideran como centrales en sus vidas y para formular juicios razonables y revisables a través del diálogo de grupo estructurado, guiados por un facilitador adulto que les ayude a navegar su proceso de pensamiento en evolución. P4C ahora es practicado en todo el mundo y ha sido reconocido por la UNESCO como un modelo pedagógico por y para niños. 
benefician de la atmósfera filosófica creada por sus indagaciones colectivas -una atmósfera de reflexión que estimula la investigación y que lleva las expresiones creativas a nuevos niveles de percepciones conceptuales y de matices estéticos-. El objetivo de este artículo es poner un poco de trabajo teórico necesario para justificar una alianza entre el zining y la indagación filosófica dirigida por jóvenes, dos prácticas importantes que funcionan fuera de la corriente dominante y que pueden arrojar algo de luz sobre los (mal)entendidos convencionales de la juventud ilustrando caminos innovadores y diseñando deliberadamente espacios para que las voces de la juventud surjan y prosperen. Es mi deseo que estas conclusiones puedan ser útiles para los educadores alternativos comprometidos con la protección y la creación de oportunidades para que los jóvenes se pregunten e imaginen sus caminos hacia la reflexión.

La niñez es un contexto relativamente nuevo para la filosofía y el zining -uno controversial y susceptible a serios desafíos-. Yo voy por lo tanto a empezar este artículo poniendo de relieve los valores que se comparten entre zining e indagación filosófica para aclarar sus compatibilidades como prácticas que enfatizan la participación, la iniciación a la auto experimentación y así tener el potencial de politizar y transformar a los comprometidos en ello. Luego voy a discutir la idea de que las voces marginales en el zining pueden enriquecer el proyecto de $\mathrm{FpN}$ de replantear la niñez ofreciendo nuevos roles para los jóvenes que más tarde confirmarán sus capacidades y valores. Finalmente, voy a explorar los asuntos de la autoridad adulta que podrían surgir del zining como una propuesta a la extensión del modelo de comunidad de indagación filosófica y sugerir condiciones que podrían ayudar a legitimar este proceso. Para el propósito de este artículo, el término "indagación filosófica" se entenderá como el modelo CIF; "zining" hará referencia a la creación de los zines; "juventud" va a ser considerada incluyendo a niños, niñas y adolescentes, con "niñez" voy a denotar el tiempo que ocurre entre la escuela primaria y la edad de votación (de 6 a 16 años aproximadamente). Los conceptos de 
diseñar un espacio para voces reflexivas. relacionar el ethos del zine con la indagación filosófica dirigida por jóvenes

"voz" y "espacio" van a ser aclarados a medida que avanza el artículo, pero por ahora pueden ser definidos respectivamente como la libertad de expresar una perspectiva y la oportunidad disponible de tales expresiones.

\section{zining e indagación filosófica: un ethos compartido}

En mi opinión, el ethos compartido del zining y la indagación filosófica puede ser extraído del imperativo liberador de crear espacios para darle voz a lo que más importa. Encuentro los zines particularmente interesantes como complemento al modelo de comunidad de indagación filosófica porque representan para los ciudadanos comunes una oportunidad sin precedentes de comunicarse en profundidad con audiencias específicas sobre soluciones particulares $\mathrm{o}$ preocupaciones a través de un medio de autopublicación altamente manejable. Con raíces en el trabajo de los panfletistas políticos americanos y europeos del siglo XVIII -especialmente Thomas Paine- y de los escritores de ciencia ficción de los años 1930, los zines son un medio híbrido que combina palabras e imágenes en publicaciones de tipo revista o lo que Williamson (1994) astutamente llama un "sitio relativamente no estudiado de bricolaje posmoderno y cultura participativa". Aunque su amplitud y diversidad desafían la categorización, los zines tienden a reflejar criterios comunes de las autopublicaciones, sin ánimo de lucro, no comerciales y no profesionales, independientes de cualquier grupo o interés. Por supuesto, en la era digital, internet parece cumplir la mayor parte de la misión de los zines de una forma posiblemente más eficaz, incluyente y accesible: prácticamente cualquiera puede hacer un blog, twittear, crear un sitio web y escribir en un foro. Sin embargo, a pesar de algunas excepciones notables, los zines se diferencian del contenido en línea en términos de formato, propósito y esfuerzo. Sobre todo, los zines son publicaciones reales completamente salidos de medios mixtos planeados, creados individualmente o por un pequeño grupo de personas con ideas semejantes-, un esfuerzo de labor intensiva, intencional y que consume más tiempo que las tácticas de retazos de los medios 
sociales o el carácter periodístico de los blogs 5 . No obstante, el logro innegable que encontramos en los zines, estos requieren de un trabajo fuerte. Como observa Chu (1997, p. 80), “el proceso de publicación del zine demuestra los serios esfuerzos desplegados por los jóvenes para tal empresa"6.

Los zines pueden ser considerados como una revolucionaria herramienta de comunicación en el sentido en que han habilitado espacios donde personas comunes pueden poner voz a sus ideas, preocupaciones y convicciones en un paisaje cultural, político y mediático que ha fallado enormemente en representar la realidad que viven. En las palabras de Fredric Wertham, un psiquiatra que estudió el fenómeno zine en profundidad:

Los zines dan una voz a las personas anónimas del cotidiano. La idea básica es que alguien se sienta y escribe, colecta, dibuja o edita un manojo de cosas que le interesan o le preocupan profundamente... y las distribuye. La creación del zine es un proceso directo que permanece bajo el control del escritor todo el tiempo. Quizás su faceta más destacada es que existe sin ninguna interferencia externa, sin ningún control de arriba, sin ninguna censura, sin ninguna supervisión o manipulación (SPENCER, 2008, p. 71).

Además, el hecho de que adultos jóvenes con edades entre 15 y 30 años han sido históricamente los más ardientes y prolíficos creadores de zines (zinesters) hacen

\footnotetext{
${ }^{5}$ Muchos teóricos del zine hacen eco a mi opinión, notablemente Piemeier (2008) quien sostiene que "los zines requieren un nivel de toma de decisiones que los blogs no necesitan.

${ }^{6}$ Dada la relativa libertad de los medios interactivos, en mi opinión, la idea de un zine "digital" puede ampliar las posibilidades estéticas, permitiendo a las imágenes y palabras típicas del zine en papel coexistir junto al contenido audio y video, dando como resultado publicaciones de "bricolage" más inclusivas que reconocen los amplios significados que las diferentes preferencias creativas permiten, mientras hacen honor a las publicaciones online más ecológicamente. En la comunidad del zine, sin embargo, esta proposición es controvertida: muchos han argumentado de manera convincente que la materialidad tangible de los zines en papel es esencial para el espíritu del zining porque facilita un encuentro más íntimo, afectivo y personal entre los zinesters y sus audiencias en una era dominada por las pantallas y la realidad virtual (Piepmeier, 2008, Bartel, 2004, Chidgey, 2006). Aunque estoy muy de acuerdo con estas preferencias estéticas, creo que el ethos del zining puede ser preservado en la forma digital si se presta cierta atención al diseño, y que las nuevas generaciones de zinesters deben tomar los medios digitales como opciones creativas válidas con las que deben identificarse. El diseño estético de los zines -deliberadamente no lineales, incluso caóticos con el fin de reflejar su contenido ecléctico y multifacético- puede ser reproducido en forma digital con ciertas elecciones concienzudas relacionadas con la manera en que el contenido debe ser organizado. Más allá de las consideraciones estéticas, si el zining se va a alinear con la indagación filosófica, el valor potencial de los zines digitales debe medirse a nivel ambiental, financiero y de accesibilidad; el abandono del papel debe engendrar nuevos propósitos.
} 
diseñar un espacio para voces reflexivas. relacionar el ethos del zine con la indagación filosófica dirigida por jóvenes

del medio algo irresistible como complemento al modelo CIF7. En Notes from Underground, Duncombe (2008, p. 204-205) sostiene que "en las sombras de la cultura dominante, los zines y la cultura subterránea (underground culture) señalan un espacio libre: un espacio para imaginar y experimentar con nuevas e ideales formas de pensar, comunicar y ser". Esta descripción de espacio podría representar justamente la atmósfera buscada en CIF. Como prácticas, tanto el zining como la indagación filosófica se esfuerzan por crear un espacio para que las voces sin filtro se embarquen en la creación de sentido que ellas mismas consideren significativo y valioso. A pesar de sus raíces separadas y sus respectivas idiosincrasias, comparten características definitorias clave -cinco de las cuales aparecen como especialmente relevantes para su ethos: i) su ideal democrático y participativo, ii) su ética de "hágalo usted mismo", iii) su espíritu experimental, iv) su influencia politizante, y v) su potencial transformativo-.

Primero, el zining y la indagación filosófica comparten un ideal democrático y participativo en el que defienden los diferentes compromisos públicos en el diálogo de las soluciones que les afectan. Proponen la inclusión, estimando una multitud de voces y valores -un bricolaje literal y metafórico de perspectivas- no sólo las dominantes, rechazando así los principios meritocráticos que evalúan la dignidad basándose en criterios excluyentes como la edad, la riqueza, el estatus político o el capital cultural. Ambas prácticas se esfuerzan por eliminar las jerarquías posicionando sus participantes en igualdad de condiciones -como lo decía Duncombe, incluso los "perdedores" tienen un lugar porque su inhabilidad para ganar en cierto tipo de carreras los hace representativos de importantes puntos de vista y modos de vida alternativos (DUNCOMBE, 2008, p. 25). Del mismo modo, en una CIF, los miembros con los más altos grados o la más alta popularidad no son necesariamente más destacados que sus contrapartes supuestamente desvalidas -

${ }_{7}$ Chu (1997) se refiere a los zines como "uno de los únicos sitios independientes para la expresión de decenas de miles de jóvenes en un ambiente de medios dominados por los intereses corporativos de los adultos. 
incluso podrían verse eclipsados o superados por aquellos que de otro modo estarían más abajo en la escala usual de "méritos" -. Curiosamente, ambas prácticas también han sido criticadas por no poder simbolizar el ideal democrático y participativo pues sus defensores tienden a ser blancos provenientes de la clase media -aunque esta tendencia no es en modo alguno deliberada ${ }^{8}$-. Aun así, la participación abierta sigue siendo su estrella polar; ellas aspiran a permitir la participación de manera activa en el intercambio de conocimientos que incluye la identificación positiva con principios comunes, pero también la resistencia a las normas sociales que generan desconfianza. Más allá de la libertad para describir realidades desde diferentes perspectivas, el zining y la indagación filosófica animan a los individuos a explorar y formular reclamos normativos sobre cómo deberían ser esas realidades, redefiniendo así su mundo ideal y los caminos para llegar a él. De esta forma, promueven la ciudadanía democrática: como escribe Lipman (1988, p. 60), “los buenos ciudadanos son ciudadanos reflexivos, que insisten vigorosamente en que los ideales no sólo deben ser profesados, sino que deben ser operados e implementados.

Segundo, tanto el zining como la indagación filosófica celebran la ética de "hágalo usted mismo" (o DIY por su sigla en inglés) animando a la gente a entender su falta de experiencia o su nivel de aficionado no como un símbolo de ineptitud sino de amor genuino por la autoexpresión y la construcción de comunidad. En el zining, la ética del DIY está completamente explícita: inspirados en los movimientos punk y sci-fi, los zinisters encarnan la noción de que cualquiera puede tomar parte y hacer oír su voz. Además, como observa Bartel (2004, p. 22), “la pregunta no es solamente ¿por qué no hacerlo yo mismo?, sino ¿por qué el trabajo de otro va a merecer mayor reconocimiento o legitimidad que el mío?". En una comunidad de indagación filosófica, este ímpetu toma la forma de una búsqueda colectiva de sabiduría: los miembros aprecian su capacidad para tomar las grandes preguntas de la vida sin la asistencia de filósofos profesionales, convencidos de que pueden aprender de las

8 Wan (1999, p. 17), habla sobre el tema del privilegio en los zines, mientras que Chetty (2014) describe la subrepresentación racial en FpN. 
diseñar un espacio para voces reflexivas. relacionar el ethos del zine con la indagación filosófica dirigida por jóvenes

experiencias generales de vida de los otros "-la comunidad de indagación es de cierto modo un aprendizaje de grupo y es por lo tanto un ejemplo del valor de la experiencia compartida-" (LIPMAN, 2003, p. 93). En ambos casos, la esperanza es que la ética del DIY se extrapole en otras esferas de la vida, resaltando la acción personal como oposición a la pasiva docilidad. El sentido de la urgencia se vuelve irresistible: la vida está pasando ahora ¿cómo podemos dirigirla? En una CIF, los miembros responden escogiendo las preguntas que reflejan mejor lo que les concierne en el momento; para los zinisters, la autopublicación preserva los recuerdos del presente en lo que Chidgey (2013, p. 667) llama una "estrategia de supervivencia: no perder la identidad de uno, sus creencias ni sus esperanzas".

Tercero, el zining y la indagación filosófica cultivan un espíritu experimental, resaltando el proceso por encima de los resultados y permaneciendo en la idea de un estado de perpetuo progreso inacabado. El propósito de una CIF nunca es resolver una cuestión filosófica sino lograr un acuerdo temporal de una investigación a vida que puede ser reabierta en el momento en que nuevas experiencias sean aptas para tomar parte en ella: "la filosofía", escribe Lipman, "provee ideas sobre las cuales la gente puede reflexionar -ideas que no se agotan porque son persistentemente contestables- (CHIDGEY, 2013, p. 160). De modo similar, Gordon (2012, p. 4) anota que "el contenido de los zines suele encontrarse como un trabajo en progreso", permitiendo a sus creadores ser más auténticos en sus exploraciones conceptuales y creativas ya que no operan con las restricciones de algo completo. Como resultado, ambas prácticas pueden ser descritas como lúdicas -ellas crean un espacio de experimentación libre de presión donde los individuos pueden experimentar con ideas no familiares aumentando el gusto por el ensayo-error-. Dicho de otro modo, el zining y la indagación filosófica ofrecen oportunidades similares para realizar diferentes subjetividades posibles -Asbell lo llama "espacios para el juego de la identidad", donde cualquier cosa se puede intentar con relativa seguridad ya que la realización no está dirigida hacia el público en general sino a un determinado público 
de "desconocidos simpatizantes". De la misma forma en que la investigación evita el dogmatismo, los zines multiplican los puntos de vista inéditos. Como escribe Radway (2001, p. 18), "los zines constituyen una tensa cacofonía de voces contundentes; son ventrílocuos de posiciones subyugadas que intentan tomar el control y dominio... realizando sin cesar. Multiplican exuberantemente las personas que desafían las exigencias las cuales sólo tienen una vía y no otra".

Cuarto, gracias a esta poderosa experimentación en performatividad, el zining y la indagación filosófica pueden ejercer una influencia politizadora ayudando a los individuos a darse cuenta de su propio poder como se puede ver en sus testimonios como zinesters e investigadores. A través de sus reportes personales, que pueden tomar forma de anécdotas o comentarios, los zinesters dan testimonio de sus propias vidas, "haciendo más compleja la realidad al dar voz y experiencia personal a proyectos políticos" (GORDON, 2012, p. 5) y “desafiando los límites de lo que es comprendido como legítimamente político" (COLLINS, 1999, p. 68). De forma similar, una CIF depende de sus miembros para producir tantas consideraciones como sea posible para informar la posición de todo el grupo en la pregunta elegida, creando un espacio para narraciones personales en forma de ejemplos y contraejemplos, analogías aclaradoras y perspectivas que subvierten y problematizan sucesivamente las suposiciones. Lipman (2003, p. 110) describe el proceso como "una combinación de conmovedoras observaciones fragmentadas en un todo significativo" uno que les ayuda a juzgar el poder político de su propia voz.

Quinto y último, gracias a sus características participativa, hágalo usted mismo, experimental y politizadora, tanto el zining como la indagación filosófica tienen el potencial de ser transformadores para quienes están comprometidos en ello. El celebrado zinester Mike Underlay (1989, p. 35) resalta cómo el zining cambia las prioridades y perspectivas personales: “Están cambiando la vida de las personas...con seguridad cambiaron la mía. Los alimentos que como, la ropa que visto, la música que escucho, las ideas en las que creo, y los lugares en los que quiero vivir han sido 
diseñar un espacio para voces reflexivas. relacionar el ethos del zine con la indagación filosófica dirigida por jóvenes

todos influenciados (y no sutilmente) por mi constante inmersión en el mar de las alternativas". De la misma manera, la experiencia en la CIF ha impulsado razones propias más profundas: por ejemplo, los testimonios de jóvenes en Brila incluyen declaraciones como "la filosofía me enseñó lo que quiero en mi vida y lo que espero de la vida" y "ahora puedo alcanzar nuevos niveles de pensamiento" y "ser creativo en formas que nunca había imaginado"9. En ambas prácticas, los individuos forman y asumen posiciones en el mundo de maneras en que no lo habían hecho antes, transformándose de objetos en sujetos. Aquí la noción de la literatura del zining de sujeto "resistente" que está "comprometido en un proyecto de construcción transformativa del mundo" (DEGRAVELLES, 2011, p. 59) también refleja la característica trascendente de la indagación filosófica ya que "no comprometerse en ir más allá de los logros anteriores es arriesgarse a entrar en una forma de indagación que carece de integridad" (LIPMAN, 2003, p. 246). Por extensión, debido a su potencial de transformación, ambas prácticas pueden convertirse en fuente de esperanza y cambio para los individuos -una posibilidad importante para la juventud cuya voz ha sido ampliamente ignorada-.

\section{la juventud marginalizada, voces sin filtro: re-imaginando la niñez}

Entre sus logros, el movimiento FpN ha sido célebre por ayudar a inspirar una nueva concepción de la niñez demostrando la validez de las voces de los jóvenes. El modelo CIF caracteriza a los jóvenes como personas en su propio derecho -por oposición a los adultos en sus quehaceres- y ayuda a fortalecer su emergente sentido de la acción a través del compromiso significativo en la indagación colaborativa ${ }^{10}$. Controversialmente, Lipman y los filósofos de la niñez que él inspiró tienen suposiciones problemáticas resaltadas en muchos reportes sobre las capacidades de la

\footnotetext{
9 Para conocer los testimonios completos, por favor vea www.brila.org/about.html\#testimonials

${ }_{10}$ Lipman (1988, p. 194) afirma que muchas teorías del desarrollo "asumen con frecuencia que la infancia es una preparación para la vida adulta y hay que verla como un medio para alcanzar una meta o como una condición incompleta en dirección hacia una completa".
} 
juventud, haciendo un llamado urgente para crear espacios en los que las mentes jóvenes puedan deliberar seriamente sobre las soluciones que les interesan. Como escribe Kennedy (2006, p. 12), “La diferencia del niño hace de ella un texto que es lo suficientemente lejano en el tiempo y en la experiencia para que la teoría no sea sólo para apropiarse, sino para colonizar". En efecto, entre los esfuerzos por las iniciativas de $\mathrm{FpN}$ y otros métodos educativos con similares misiones de dar voz a la juventud, persiste la resistencia a la re-concepción de la niñez. Giroux (1998, p. 24) captura esta desafortunada realidad:

La juventud como una categoría cambiante, compleja y contradictoria rara vez es narrada en la esfera pública dominante a través de las diversas voces de los jóvenes. Puesto que se le prohíbe hablar como agente moral y político, la juventud se vuelve una categoría vacía donde no habitan los deseos, fantasías e intereses del mundo adulto. Esto no es para sugerir que los jóvenes no hablan; simplemente... es el rechazo al poder de hacer que el conocimiento sea consecuente con el respeto de sus propias necesidades colectivas.

De muchas maneras, esta representación de la juventud refleja las descripciones de las voces marginalizadas que impregnan la escolaridad y cultura del zining. Como otras minorías desprovistas de derechos que han adoptado el zining, especialmente el feminismo y los grupos no convencionales-, la juventud representa un importante subconjunto social que es descuidado, o al menos no representado. Mientras las diferencias entre ellos abundan en términos de género, etnia y estatus socioeconómico, etc., juntos forman un paquete de desvalidos -un grupo cuya ausencia de poder les relaciona sin unificarles. El zining, sin embargo, tiene el potencial para forjar esas uniones de manera que apoyan y extienden los propósitos del modelo CIF proporcionando otra salida para una expresión sin filtros. Después de todo, el ethos del zining ha facilitado el despliegue de muchas narrativas desconocidas, desde la formación de los zines de Riot Grrrl en los años 90 que fueron más allá de los géneros binarios (RADWAY, 2011, p. 12) hasta los extraños zines activistas más recientes que replantean las representaciones que los medios masivos hacen de las "víctimas" del SIDA (LONG, 2000, p. 403). Como Sinor (2003, p. 243) escribe, "Debido a que la historia que nos cuentan es la de un excluido, ésta, como 
diseñar un espacio para voces reflexivas. relacionar el ethos del zine con la indagación filosófica dirigida por jóvenes

muchas de las historias narradas por los invisibles, debe ser contada de manera que rompa las expectativas y que interrumpa las suposiciones. Desde mi perspectiva, la activación de la voz de los jóvenes no sólo como investigadores filosóficos sino también como zinesters tiene el potencial para ayudar a re-imaginar la niñez introduciendo nuevos posibles roles para los jóvenes, específicamente dos: i) como productores de cultura y ii) como historiadores sociales.

Primero, como zinesters, los jóvenes pueden tomar el papel de productores culturales simplemente por el hecho de crear un zine. Es un cambio significativo dado que ellos han sido usualmente relegados al estatus de consumidores culturales, ingiriendo contenidos creados por adultos bajo la forma de libros de imágenes, filmes animados, juegos de video y similares, a menudo creados con intereses corporativos en mente. Parece claro declarar que la representación no diluida de la niñez es casi inexistente en la cultura dominante. En lugar de eso son descritos con representaciones caricaturales cargadas de prejuicios, creadas por los adultos sin su participación. Como productores culturales, sin embargo, a través de formatos como los filozines, los jóvenes pueden afirmarse ellos mismos como escritores, ilustradores, fotógrafos y artistas de nuevos medios, construyendo a través de estas formas creativas una serie de alternativas sobre la experiencia de la niñez e incluso posiblemente haciendo surgir nuevos ítems culturales sobre la capacidad de los jóvenes para reemplazar estereotipos pasados de moda. Después de todo, como anota Klaus (2012, p. 1-2), el poder de la creación cultural reside en su potencial para "sacar de quicio y desafiar la forma como 'normalmente' vemos y hacemos las cosas... (y) en este sentido puede ser comprendida como una intervención en el proceso de creación de significado". Además, el ethos del zining puede proteger a la juventud del escrutinio en la medida en que celebra la expresión en bruto en vez del carácter más pulido y escrito de muchas tareas escolares, abriendo posibilidades para aumentar la comprensión adulto-niño. Como escribe Lipman (1988, p. 191), "las diferencias entre las perspectivas de adultos y niños representa una invitación para la experiencia 
compartida de la diversidad humana en lugar de una excusa para la hostilidad, represión e inculpación intergeneracional". Como producciones culturales, los zines ofrecen un espacio para que las voces jóvenes sin filtros sean reflexivas y, con algo de suerte, tomadas más en serio.

Segundo, como zinesters, los jóvenes también pueden tomar el papel de historiadores sociales publicando narraciones en medios mixtos de sus experiencias vividas como un grupo marginalizado. Aunque los historiadores están en desacuerdo con el valor de dichas narrativas para su disciplina universal, lo que parece claro es que una lupa social pues la historia ha "demostrado la utilidad -y de hecho la calidad invaluable- de todas las clases de documentos que antes fueron tenidos en baja estima" (SAMUEL, 1985, p. 6). Los zines pueden ser tomados como parte de esta documentación porque "son actualmente uno de los medios por los cuales las historias escondidas salen a la luz" (DEGRAVELLES, 2011, p. 63). Ya que los jóvenes pueden articular su experiencia contextualizada de la niñez, mientras los adultos sólo pueden especular, ofreciendo su propia versión de los datos de la historia social, contribuyen a la reunión de la información que puede iluminar el subconjunto social incomprendido que ellos representan. Su encuentro más reciente con algunas realidades humanas -escolaridad, injusticia, violencia, miedo a la muerte, por nombrar sólo algunos- también puede proveer perspectivas más claras sobre la forma en que la juventud como una categoría navega y negocia el mundo de los adultos en el que habitan y que eventualmente heredarán. Por ejemplo, en Brila, la escuela es un tema consecuentemente popular en la expresión creativa de los filozines: no es una sorpresa que los jóvenes tengan muchas nociones sobre los problemas de autoridad y aprendizaje dado que sus vidas cotidianas están dominadas por sus experiencias escolares. Por extensión, desde mi punto de vista, el contenido de los zines que refleja sus preocupaciones presentes -en el caso de la escuela, si deberían tener más opinión en la elección de sus clases, en la contratación de profesores, en sus enfoques 
diseñar un espacio para voces reflexivas. relacionar el ethos del zine con la indagación filosófica dirigida por jóvenes

educativos, etc.- puede proporcionar lo que Boellstorff (2004, p. 375) llama "una ventana al extenso sistema de la significación".

Así pues, a través del zining, los jóvenes pueden asumir los roles de productores de cultura y de historiadores sociales, que pueden llevar sucesivamente a la formación de su propio discurso comunitario -con su propia forma de comunicar sus metas, valores y puntos de ventaja comunes. Para Lipman (1988), una construcción de comunidad semejante es esencial para dirigir el desarrollo: "la formación de comunidades infantiles, donde la franqueza y la confianza se mezclen libremente con las reflexiones, el razonamiento y la investigación, proporciona un soporte social necesario durante esos años críticos en que los niños están... esforzándose por establecerse como individuos maduros y responsables" (LIPMAN, 1988, p. 197). Ahora, para que esos desarrollos se traduzcan en una re-imaginación significativa de la niñez que busca reconocer y corregir el problema de las voces jóvenes marginalizadas, la carga cae sobre los adultos que deben aumentar su complacencia para percibir a los jóvenes como dignos de confianza -el foco de mi siguiente sección-. Por otra parte, como previene Lipman, "si los niños deben ser "vistos y no escuchados", su silencio nos priva a los demás de sus percepciones" (LIPMAN, 1988, p. 194).

\section{el adulto como diseñador de espacios de voz: retos y condiciones}

$\mathrm{Si}$, como un espacio para la voz, el ethos compartido del zining y la indagación filosófica tiene mucho que ofrecer a la juventud, ¿cómo se les puede presentar en una forma apropiada, adecuándolo a su madurez y experiencia? Parece probable que en alguna medida los adultos tienen que entrar en la ecuación. Con seguridad, los jóvenes tienen que descubrir ambas prácticas en sí mismos y elegir el comprometerse con ellas a su propia medida, pero es posible que, dado que esas prácticas no están ampliamente disponibles en muchos contextos educativos, un adulto deba organizar el espacio para la voz de manera que los jóvenes tengan incluso acceso al zining y la 
indagación filosófica como opciones que vale la pena considerar. Aún puede la ética del DIY realmente sobrevivir si las circunstancias piden más del enfoque "hágalo usted mismo“" (con la guía de un adulto). El problema de la autoridad adulta es una posible amenaza a la integridad de ambas prácticas -una realidad que ofrece desafíos específicos para la exposición de la juventud al zining y la indagación filosófica, mientras que también piden ciertas condiciones bien delineadas.

Para empezar, la noción de una pedagogía del zine ha generado preocupaciones comprensibles en los zinesters que temen que la domesticación del zining en la educación lo va a institucionalizar sin coherencia ${ }^{11}$. En vez de eso, muchos han aconsejado que los adultos interesados en el potencial educativo de los zines creen tareas "tipo zine" que planten la semilla de la cultura zining sin co-elegirlo. Otros han advertido contra la introducción de zines en las escuelas sin un sentido realmente claro de su historia y misiones ideológicas, ya que una representación simplista puede llevar a elecciones pedagógicas sin dirección, tales como el deseo de asignar grados a los zines, establecer reglas creativas claras o prescribir temas de estudio como la justicia social. Por mi parte, estoy extremadamente preocupada con la idea de un regulador adulto vigilando un grupo de jóvenes zinesters, aunque reconozco que la juventud tiene pocas o ninguna oportunidad para la expresión crítica y creativa en su experiencia educativa, haciendo la unión del zining y la indagación filosófica demasiado tentadora para ser descartada. Para justificar una pedagogía del zine, Sinor (2003, p. 240) anota que ella descubrió los zines siendo adulta ya que su "adolescencia fue mucho menos informada, mucho menos autorizada y mucho más marcada por la conformidad pasiva". Esto puede ser cierto para muchos jóvenes y es por eso que pienso que el ethos del zining debe serles presentado a través de la guía cuidadosa de los adultos. Como la cofundadora de FpN Ann Sharp argumenta, "uno tiene que estar alerta al significado ético y político

\footnotetext{
11 Sinor (2003) hace bien este punto: "Los zines son parte de una subcultura próspera, que desprecia la comodidad y el consumismo... de hecho, los zinesters escriben exactamente contra la misma audiencia que tiene este ensayo entre sus manos" (p. 242).
} 
diseñar un espacio para voces reflexivas. relacionar el ethos del zine con la indagación filosófica dirigida por jóvenes

de su experiencia -tanto emocional como conceptualmente- antes de poder sentir y luego articular que hay algo malo con ello" (GREGORY, 2011, p. 204).

Para proteger el ethos compartido del zining y la indagación filosófica, el adulto, como creador del espacio para la voz, primero debe estar dispuesto a reimaginar la niñez en las formas antes descritas. Kennedy (2006, p. 17-21) describe este proceso como un tipo de hermenéutica que permita una nueva postura interpretativa:

La situación hermenéutica comienza cuando nosotros (adultos) confrontamos un texto (niño) del que nos hemos distanciado, creando así una relación en la que encontramos tanto familiaridad como extrañeza y un cierto nivel de alineación y de falta de entendimiento... Esto implica una nueva auto-comprensión, que incluye al menos una comprensión del niño como un fenómeno positivo -un interlocutor real, un ser completo (full-fledged) [...] A través de mi diálogo con los niños y la niñez, adquiero un nuevo patrón para la experiencia de lectura.

Sucesivamente, percibir a los jóvenes como "interlocutores reales" requiere que los adultos establezcan ciertas condiciones en el espacio que diseñan para asegurar que las voces jóvenes pueden comunicarse de manera segura, sin intervención autoritaria innecesaria. En mi opinión, estas condiciones pueden dividirse en consideraciones específicas para el zining y requerimientos inspirados por el modelo FpN. Más abajo sugiero una serie de posibles condiciones iniciales para que los adultos autentiquen la práctica del zining de los jóvenes:

- Proteger a la juventud como una población vulnerable. Para bien o para mal, en muchas circunstancias, los jóvenes son considerados legalmente como población vulnerable hasta que alcanzan la edad de votar. Como tal, ciertas dimensiones del zining como la violación de derechos de autor y los discursos insurrectos deben dejarse de lado o al menos problematizados de manera a siempre proteger a los jóvenes de la violación de leyes. Los problemas relacionados con la censura también deben ser discutidos para asegurar que los jóvenes puedan establecer directivas de edades apropiadas para la producción de sus zines.

- Permitir a los jóvenes organizar su propia agenda. Los adultos deben resistirse a imponer orden o significado en el contenido de los zines producidos 
por los jóvenes, y más bien permitirles elegir sus propios temas y estilos creativos. Ciertas elecciones estéticas y conceptuales pueden parecer ininteligibles e incluso triviales para los adultos, pero de hecho para los jóvenes representan una profunda experimentación con la libertad de expresión. En efecto, como Duncombe (2008, p. 39) escribe, a través del "rechazo de algunos zines de tener sentido", o su tono imaginativo o de parodia, "los zines ejecutan la diferencia que están tratando de hacer". Por medio del zining, la juventud imagina el mundo a su imagen.

- Fomentar la comodidad de los jóvenes con la voz. Hay que darles el tiempo de crecer en su nueva oportunidad de expresión. Los adultos no deben malinterpretar las respuestas iniciales de miedo, malestar, ansiedad y rechazo de jóvenes cuyas ideas probablemente nunca antes fueron tomadas en serio. La comodidad con la atmósfera DIY experimental del zining no es necesariamente automática -los jóvenes pueden necesitar espacio para desarrollar su autoeficacia a medida que empiezan a jugar nuevos roles y a adoptar la posibilidad de fallar. Compartir el contenido del zining no debería ser coactivo sino gentilmente estimulado.

- Evitar evaluaciones condescendientes. Los adultos pueden tener tendencia a maravillarse con la calidad y sofisticación inesperadas en el contenido de los zines de los jóvenes, pero deben más bien esforzarse por producir una retroalimentación para asegurar que el proceso del zining es intrínsecamente válido para los jóvenes y no meramente un instrumento para ganar la aprobación de los adultos. Al mismo tiempo, el adulto no debe ser el árbitro de la "grandeza" del zine: el objetivo del zining no es el de producir obras maestras sino el de explorar nuevas ideas y formas creativas por medio de una contribución original, sin importar cuán poco pulida o tentativa sea.

Para mejorar aún más la práctica del zining de los jóvenes, creo que la literatura extensiva de la comunidad de indagación filosófica sobre la facilitación 
diseñar un espacio para voces reflexivas. relacionar el ethos del zine con la indagación filosófica dirigida por jóvenes

puede ser de gran ayuda. Particularmente, los siguientes tres requerimientos pueden reducir más el riesgo de la autoridad adulta mientras expanden el potencial del zining como una experiencia emancipadora para la juventud:

- Enfocarse en el proceso más que en el contenido. Se espera de los facilitadores de CIF que den prioridad a las voces de los jóvenes absteniéndose de ofrecer sus propias contribuciones filosóficas al diálogo y que en su lugar se enfoquen en las intervenciones cuyo procedimiento sea ayudar a los jóvenes a mantenerse en la ruta y a seguir la línea de la investigación. Además, los facilitadores se esfuerzan por dar reflexiones prontas y profundas sin proporcionar respuestas a través de movimientos cuidadosos que motiven el pensamiento crítico y creativo: piden definiciones y ejemplos para aclarar un significado, miden el grado de acuerdo o desacuerdo entre los miembros del grupo, se detienen en las inconsistencias conceptuales para aumentar los matices, ayudan a resaltar la implicación de las posiciones de manera que puedan ser reforzadas y fomentan nuevas perspectivas y posibilidades. En términos coloquiales, refinan el arte de saber cuándo empujar o cuándo contener. Aplicado al zining, esta experiencia procedural puede permitir a los adultos ayudar a la expresión creativa de los jóvenes sin intervenir en el contenido -en su lugar, estimulan la reflexión sobre la elección del tema y el estilo que pueden hacer más compleja la aparición de las perspectivas de los jóvenes. Cuando se ven frente a tópicos y formas que antes no conocían y se disponen a explorarlos, los jóvenes pueden sintonizarse mejor con las cuestiones políticas, éticas y sociales a través de su práctica del zining.

- Animar la responsabilidad hacia la sociedad. Además de fomentar el pensamiento crítico y creativo en los jóvenes, también se espera de los facilitadores que alimenten el pensamiento cuidadoso, entendido como la capacidad de ser respetuoso con los otros por medio de contribuciones responsables e inteligentes en vez de una conversación interesada que 
descarrile el progreso de la investigación. Las voces individuales claramente tienen importancia en una CIF, y una investigación realmente democrática debería reflejar las intervenciones de cada uno, pero el espíritu colaborativo de la co-indagación en una cuestión con sentido toma prioridad sobre proveer una plataforma improvisada para un miembro dominante. En consecuencia, los facilitadores deben ser cuidadosos para animar a los jóvenes a hacer conexiones entre las ideas y a construir sobre las contribuciones del otro, mientras proporcionan también ocasiones regulares para que ellos evalúen la participación para asegurar la inclusión, la autorregulación y la escucha atenta. Aplicada al zining, este compromiso con los otros puede cultivar en los jóvenes un sentido de responsabilidad sobre las posiciones y los efectos que sus zines producen a través de la consideración por su audiencia. Adicionalmente, la mentalidad de "economía del regalo" del zining (intercambio amigable de zines en lugar de ventas impersonales) puede ser adaptada como un test de sinceridad para que los jóvenes zinesters eviten el contenido narcisista y auto promocional en detrimento de auténticas expresiones de construcción de sentido -el verdadero "regalo" de los zines.

- Fomentar la metacognición y la autocorrección. Finalmente, una dimensión distintiva del modelo CIF es su énfasis en las evaluaciones metacognitivas que invita a la autocorrección en los jóvenes. Se espera de los facilitadores no sólo que ayuden a los jóvenes miembros a producir mejores pensamientos sino también que entiendan lo que fortalece o debilita sus pensamientos de manera que tengan las herramientas metacognitivas para corregirse ellos mismos en el futuro. Después del diálogo, los facilitadores inician un período de reflexión durante el cual los jóvenes miembros se evalúan como grupo en términos de su propio pensamiento crítico, creativo y cuidadoso, y establecen estrategias para mejorar. Esta apropiación de su aprendizaje y crecimiento equipa a los jóvenes con disposiciones hacia la autocorrección que abarca la comodidad y la 
diseñar un espacio para voces reflexivas. relacionar el ethos del zine con la indagación filosófica dirigida por jóvenes

humildad con lo desconocido en vez de la obstinación y el miedo al fracaso. Aplicado al zining, esta actitud de autocorrección metacognitiva puede ayudar a desarrollar en la juventud más resiliencia cuando abordan ideas y tareas que les son poco familiares y a evaluar mejor los méritos y deficiencias de su trabajo. Además, con ayuda de los adultos, pueden aprender a interpretar las intenciones, motivaciones y suposiciones detrás de sus diversas producciones creativas, permitiéndoles ser más conscientes de la forma como los diferentes medios habilitan diferentes tipos de voz.

Para resumir, a pesar de los desafíos considerables que merecen atención, la cuestión de la autoridad adulta no tiene que ser una amenaza para el zining como una extensión del modelo CIF, siempre que los adultos que toman la tarea de diseñar espacios para la voz de la juventud consideren e implementen condiciones como las sugeridas en este artículo y permanezcan dispuestos a evaluar sus propias capacidades como guías facilitadores.

\section{conclusión}

En este artículo, he tratado de justificar una alianza entre el zining y la indagación filosófica para jóvenes con el fin de ilustrar cómo el espíritu del zining puede proporcionar a la juventud oportunidades inestimables para arraigar el sentido existencial de sus experiencias filosóficas a través de mejores oportunidades para expresar sus pensamientos. He destacado el ethos que comparten el zining y la indagación filosófica como prácticas que se esfuerzan por crear un espacio para que las voces sin filtros se comprometan en la creación de sentido, enfatizando en sus características participativas comunes, DIY, experimentales, politizadoras y transformadoras. He argumentado que el zining y su noción de voces marginadas puede contribuir a re-imaginar la niñez que la $\mathrm{FpN}$ ha habilitado representando a los jóvenes como productores de cultura capaces e historiadores sociales de sus propias comunidades de discurso. Finalmente, he explorado los asuntos de la autoridad 
adulta que complica el ethos del zining y la indagación filosófica cuando está extendida en la juventud, sugiriendo condiciones que podrían ayudar a autenticar el uso de los zines en el modelo CIF. Si se diseñan con cuidado, los espacios de voces deliberados que he presentado pueden traer ventajas a la juventud incluyendo el aumento al acceso de formas diferentes de enseñar a través de proyectos interdisciplinarios, además de las relaciones de igualdad con los adultos, una gama de disposiciones creativas y pensativas que pueden mejorar su eficacia y un sentido auténtico de que sus voces importan. En mi opinión, tales espacios pueden legitimar su sentido de asombro, preparando así el camino para que sus voces reflexivas surjan y sean más fuertes. Los formatos híbridos como los filozines de Brila pueden servir como evidencias memorables de jornadas de pensamiento colaborativo de la juventud -pruebas tangibles de la consonancia de sus mentes. Estos artefactos filosóficos tienen el potencial de afectar la forma como la niñez es visualizada y cómo están diseñadas las dinámicas entre los adultos y los jóvenes. Como embajadores de voz, el zining y la indagación filosófica tienen mucho que enseñar a cada uno, especialmente para representar a los jóvenes como capaces pensadores considerables con ideas que vale la pena compartir. Para citar a Ducombe (2008, p. 19), "aunque el mundo de los zines opera al margen de la sociedad, sus preocupaciones son comunes a todos: cómo contar como individuo; cómo construir una comunidad que se apoya; cómo tener una vida significativa; cómo crear algo que es tuyo".

\section{referencias}

BARTEL, J. (2004). From A to zine: Building a winning zine collection in your library. Chicago: American Library Association.

BOELLSTORFF, T. (2004). Zines and zones of desire: Mass-mediated love, national romance, and sexual citizenship in gay Indonesia. Journal of Asian Studies 63(2), 367-402.

CHETTY, D. (2014). The elephant in the room: Picturebooks, philosophy for children and racism. Childhood \& Philosophy 10(19), 11-31.

CHIDGEY, R. (2006). The resisting subject: Per-zines as life story data. University of Sussex Journal of Contemporary History 10, 1-13.

CHIDGEY, R. (2013). Reassess your weapons: The making of feminist memory in young women's zines. Women's History Review 22(4), 658-672. 
diseñar un espacio para voces reflexivas. relacionar el ethos del zine con la indagación filosófica dirigida por jóvenes

CHU, J. (1997). Navigating the media environment: How youth claim a place through zines. Social Justice 24(3), 71-85.

COLLINS, D. (1999). 'No experts: Guaranteed!' Do-it-yourself sex radicalism and the production of the lesbian sex zine 'Brat attack.' Signs 25(1), 65-89.

DEGRAVELLES, K. (2011). In the ruins of zine pedagogy: A narrative study of teaching with zines. Doctoral dissertation, Louisiana State University.

DUNCOMBE, S. (2008). Notes from underground: Zines and the politics of alternative culture. Portland: Microcosm Publishing.

GIROUX, H. (1998). Youth culture: Identity in a postmodern world. Oxford: Blackwell.

GORDON, J. (2012). Sexual assault support zines as a pedagogy of hope: An exploration of zines as a method of integrating community voices into the research process. Thinking Gender Papers, 1-18.

GREGORY, M. (2011). Philosophy for children and its critics: A Mendham dialogue. Journal of Philosophy of Education 45(2), 210-211.

GUNDERLOY, M. (1989). Why publish? Rensselaer, NY: Pretzel Press.

JACOBI, T. (2007). The zine project: Innovation or oxymoron? The English Journal 96(4), 43-49.

KENNEDY, D. (2006). The well of being: Childhood, subjectivity, and education. Albany, NY: SUNY Press.

KLAUS, E. (2012). Cultural production in theory and practice. P-art-icipate 1, 1-17.

LIPMAN, M. (1988). Philosophy goes to school. Philadelphia: Temple University Press.

LIPMAN, M. (2003). Thinking in education. Cambridge: Cambridge University Press.

LONG, T. (2000). Plague of pariahs: AIDS zines and the rhetoric of transgression. Journal of Communication Inquiry 24(4), 401-411.

PIEPMEIER, A. (2008). Why zines matter: Materiality and the creation of embodied community. American Periodicals 18(2), 213-238.

RADWAY, J. (2011). Zines, half-lives, and afterlives: On the temporalities of social and political change. PMLA 126(1), 140-150.

RADWAY, J. (2001). Girls, zines, and the miscellaneous production of subjectivity in an age of unceasing circulation. Lecture, Speaker Series No. 18, Duke University.

SAMUEL, R. (1985). What is social history? History Today 35(3).

SINOR, J. (2003). Another form of crying: Girl zines as life writing. Prose Studies: History, Theory, Criticism 26(1-2), 240-264.

SPENCER, A. (2008). The rise of lo-fi culture. London: Marion Boyars.

WAN, A. J. (1999). Not just for kids anymore: Using zines in the classroom. The Radical Teacher 55, 15-19.

WILLIAMSON, J. (1994). Engaging resistant writers through zines in the classroom.

Zinebook. Disponible en : <www.zinebook.com/resource/engagingwriters>.

Recibido en: 10.10 .2016

Aprobado en: 30.10 .2016 